\title{
APROXIMACIÓN A LA CONFIGURACIÓN JURÍDICA DEL DEREGHO AL OLVIDO EN INTERNET. UN ANÁLISIS A PARTIR DE LA SENTENCIA DEL TJUE VS GOOGLE*
}

\author{
AN APPROACH TO THE LEGAL CONFIGURATION OF THE RIGHT \\ TO BE FORGOTTEN ON THE INTERNET. AN ANALYSIS FROM \\ THE JUDGMENT OF THE CJEU VS GOOGLE
}

\section{Ana Cristina GonZÁLEZ RinCÓN**}

RESUMEN: El presente artículo tiene como finalidad estudiar el derecho al olvido en Internet a partir de la sentencia contra Google del TJUE en 2014, y dilucidar su configuración jurídica. Este análisis descarta la posibilidad de considerar al derecho al olvido en Internet como un derecho fundamental nuevo, y lo coloca como una facultad adicional a los derechos ARCO, propia del derecho a la protección de datos personales, de acuerdo con lo establecido en el Reglamento General de Protección de Datos de la Unión Europea.

Palabras clave: derecho a la protección de datos personales, libertad de información, motores de búsqueda, derecho al olvido en Internet.
ABSTRACT: The purpose of this article is to study the right to be forgotten on the Internet parting from the judgment against Google of the CFEU in 2014, and to elucidate its legal configuration. This analysis rules out the possibility of considering the right to be forgotten on the Internet as a new fundamental right and places it as an additional faculty to ARCO rights, typical of the right of protection of personal data, in accordance with the provisions of the General Regulation of Data Protection of the European Union.

Keywords: data protection, freedom of information, search engines, right to be forgotten on the Internet.

* Artículo recibido el 3 de agosto de 2018 y aceptado para su publicación el 9 de mayo de 2019.

** ORCID: 0000-0003-0305-4808. Maestra en Derecho Constitucional por el CEPG de Madrid y estudiante del doctorado en el IIJ-UNAM. Correo electrónico: ana.cristina@ comunidad.unam.mx.

Boletín Mexicano de Derecho Comparado, nueva serie, año LI, núm. 156, septiembre-diciembre de 2019, pp. 1449-1475.

Esta obra está bajo una Licencia Creative Commons Atribución-NoComercial-SinDerivar 4.0 Internacional, IIJ-UNAM. 
SumariO: I. Introducción. II. Precedentes del derecho al olvido en Internet. III. De la Directiva 95/46 al Reglamento General. Lo que pasó después de la STJUE. IV. Reconocimiento final de un derecho al olvido como facultad general de borrado y sus notas distintivas. V. Conclusiones. VI. Referencias bibliográficas.

\section{INTRODUCGIÓN}

La modernidad entendió muy bien la pretensión de construir una eterna memoria (sobre estas ideas véase el comentario de Reyes 2011), pero también ha surgido el derecho al olvido para que las personas no se vean perseguidas por informaciones pasadas y se logren poner límites a la eternidad de sus datos en Internet. El derecho al olvido es la última respuesta a la necesidad surgida en Internet de preservar ciertos derechos fundamentales, como la protección de datos personales o la privacidad de las personas. No hay otra manifestación más clara de afrontar el presente que olvidar virtualmente el pasado.

En el ámbito europeo, la configuración de los contornos del derecho al olvido recayó en manos del Tribunal de Justicia de la Unión Europea (TJUE), al resolver en 2014 la cuestión prejudicial planteada por la Audiencia Nacional con motivo de un recurso interpuesto por Google contra la Agencia Española de Protección de Datos (AEPD). Paralelamente, la Comisión Europea ha considerado indispensable actualizar el marco jurídico existente para incluir el reconocimiento y alcances del derecho al olvido. Con este fin, en 2012 la Comisión Europea presentó una Propuesta de Reglamento General de Protección de Datos (Reglamento General), que fue aprobada en 2016, con su artículo 17 sobre la regulación del derecho al olvido. ${ }^{1}$

El presente trabajo se encuentra estructurado en dos partes. En primer lugar, se hace un recuento sobre el origen del derecho al olvido en Internet a partir de la sentencia del Tribunal de Justicia de la Unión Europea (STJUE) sobre el caso Google. Posteriormente, se analiza el momento posterior a dicha sentencia, y en particular lo relativo al pronunciamiento

1 Reglamento (UE) 2016/679 relativo a la protección de las personas físicas en lo que respecta al tratamiento de datos personales y a la libre circulación de estos datos, y por el que se deroga la Directiva 95/46/CE (Reglamento general de protección de datos) se puede consultar en: https://eurlex.europa.eu/legalcontent/EN/TXT/PDF/?uri=CELEX: 32016 R0679 \&from $=E \mathcal{N}$.

Esta obra está bajo una Licencia Creative Commons

Atribución-NoComercial-SinDerivar 4.0 Internacional, IIJ-UNAM.

Boletín Mexicano de Derecho Comparado, núm. 156, pp. 1449-1475. 
sobre el derecho al olvido como derecho de supresión en el caso resuelto por el Tribunal Supremo (TS) en España sobre la editorial El País y, finalmente, se analizan cinco notas distintivas para establecer un marco relativamente claro que pueda ayudar a la determinación de su configuración jurídica como facultad general de borrado en Internet.

\section{PREGedentes Del DeREGHO AL OLVIDO EN INTERNET}

La primera vez que se habló del derecho al olvido fue en la sentencia del Tribunal de Justicia de la Unión Europea el 13 de mayo de 2014. En ese momento, el TJUE resolvió el caso de un ciudadano español en contra de Google por el tratamiento de sus datos mediante el buscador, de acuerdo con la entonces Directiva 95/46 sobre protección de datos, que vino a representar el leading case del derecho al olvido en Internet. Dos años después de esa sentencia, se aprobó el actual Reglamento General del Parlamento Europeo y del Consejo, del 27 de abril de 2016, ${ }^{2}$ cuyo artículo 17 contempla el derecho al olvido.

La sentencia del Tribunal supranacional planteó diversas cuestiones en torno a la configuración del derecho al olvido. Una de las cuestiones que se destacó más allá incluso de los pronunciamientos sobre el tratamiento de datos o la responsabilidad de los buscadores en Internet es si la sentencia configuró el derecho al olvido como un derecho fundamental, o bien como una nueva denominación adoptada de alguna de las facultades existentes del derecho a la protección de datos personales (véase Arenas 2013, derechos ARCO).

En España, este debate supuso en su momento opiniones diversas entre los autores. Para algunos, el derecho al olvido se podía enmarcar dentro de los derechos, valores y principios que la Constitución española (CE) recoge (véase Pere 2012). Así, se defendió el reconocimiento del derecho al olvido como un derecho de libertad del ciudadano, a poder escoger cuándo y dentro de qué limites procede revelar datos e informaciones

2 El Reglamento General entró en vigor a los veinte días de su publicación en el Diario Oficial de la Unión Europea, pero su aplicación comenzó a partir del 25 de mayo de 2018 para todos los Estados miembros de la Unión, tiempo en el cual las empresas, organizaciones, organismos e instituciones pudieron conocer su contenido y adaptarlo para su cumplimiento. 
que forman parte de su identidad. En la medida de su conexión con el libre desarrollo de la personalidad y dignidad humana, el derecho al olvido protegería el bien jurídico reconocido en el artículo 10.1, GE, que garantiza la libertad y autonomía del individuo para actuar y desarrollar su proyecto vital. ${ }^{3}$ De manera que "se protegería a los individuos frente a la difusión de todas las informaciones personales pasadas que les puedan afectar en el futuro, con indiferencia de si afectan o no a los derechos de su vida privada" (Pere 2012, 121). Se concebiría así la hipótesis de un derecho al olvido como un derecho fundamental exigible frente a los poderes públicos y privados.

En cuanto a su posible carácter como nueva facultad del derecho fundamental a la protección de datos personales, en su momento ésa fue precisamente la intención de la Audiencia Nacional, al plantear el tercer y último bloque de preguntas en la cuestión prejudicial, ${ }^{4}$ estrictamente circunscritas a saber si de la interpretación de la Directiva 95/46 era posible derivar un derecho al olvido más allá de las facultades tradicionales de cancelación y oposición. ${ }^{5}$ En ese sentido, las conclusiones del abogado general del TJUE se pronunciaron en contra de reconocer un derecho al olvido, al afirmar que "la Directiva no establece un derecho general al olvido, en el sentido de que un interesado esté facultado para restringir o poner fin a la difusión de datos personales que considera lesivos o contrarios a sus intereses" (caso Google versus AEPD, párr. 108). El TJUE, por su parte, ni siquiera abordó la cuestión directamente como

3 Para un estudio exhaustivo sobre el derecho al olvido como nuevo derecho fundamental vinculado al libre desarrollo de la personalidad y dignidad humana, Pere (2012).

4 "Los jueces preguntaron al alto tribunal europeo si el derecho a la protección de datos incluye que el afectado pueda negarse a que una información referida a su persona se indexe y difunda, aun siendo lícita y exacta en su origen, pero que la considere negativa o perjudicial para su persona. En definitiva, se pregunta la Sala si la Directiva 95/46 de protección de datos junto con los derechos 7 y 8 de la Carta de Derechos Fundamentales de la Unión Europea amparan "el denominado derecho al olvido en Internet". Véase Hernández (2014).

5 En opinión de Artemi Rallo, los derechos tradicionales de protección de datos llamados a preservar la calidad de la información personal y el derecho individual a consentir su tratamiento encuentran difícil acomodo cuando se trata de evitar la indexación por los buscadores de información personal lícita y exacta, pero que el individuo estima que le perjudica. De ahí que la Audiencia Nacional haya apelado al Tribunal de Justicia de la Unión Europea para, partiendo del marco jurídico europeo vigente, actualice su catálogo de derechos e identifique como nueva categoría el derecho al olvido. Véase Rallo (2014).

Esta obra está bajo una Licencia Creative Commons

Atribución-NoComercial-SinDerivar 4.0 Internacional, IIJ-UNAM.

Boletín Mexicano de Derecho Comparado, núm. 156, pp. 1449-1475. 
para sostener que se reconocía un nuevo derecho al olvido. Es verdad que sí reconoció que bajo determinadas circunstancias era posible solicitar la cancelación y oposición en Internet de los datos objeto de tratamiento, incluso que tal solicitud podía ir dirigida a los buscadores de Internet, como Google; pero esto no supuso ninguna nueva figura jurídica bajo el nombre de derecho al olvido.

El análisis del derecho al olvido como una facultad dentro de las existentes de la protección de datos tuvo sus propios retos, pues ciertamente, en ese sentido, es que se aproximó la naturaleza jurídica del derecho al olvido. En efecto, derivado de la STJUE, el derecho al olvido se tradujo en una facultad reforzada de las facultades de cancelación y oposición en el ámbito de Internet, o si se quiere decir, fue la suma de las facultades de cancelación y oposición en el entorno virtual (Troncoso 2012).

Una vez aprobado el Reglamento General, la "llegada del derecho al olvido" (véase Cotino 2015), en el artículo 17 supuso la concreción del derecho a la supresión, entendido más que como las facultades de cancelación y oposición en el entorno digital, como lo suponía la Directiva 95/46, como una facultad adicional y aledaña a ellas. En concreto, la facultad de oposición mantuvo su vigencia en el Reglamento General, pero su contenido no correspondió a una posible facultad de borrado, por lo que se consideró en otro lugar, es decir, junto a ella.

\section{De la Directiva 95/46 Al Reglamento General. LO QUE PASÓ DESPUÉS DE LA STJUE}

En el seno de la Unión Europea se empezó a considerar la necesidad de establecer un marco más sólido y coherente en materia de protección de datos en la UE, que evitara la excesiva fragmentación en la aplicación de la protección de datos de carácter personal en el mismo ámbito, y que fortaleciera la seguridad jurídica de los ciudadanos europeos, operadores económicos y las autoridades públicas (Gómez 2016, Reglamento UE 2016/679); así, se dio paso a un instrumento jurídico más riguroso que en adelante regula el derecho al olvido.

Artículo 17. 1. El interesado tendrá derecho a obtener sin dilación indebida del responsable del tratamiento la supresión de los datos personales que le conciernan, el cual estará obligado a suprimir sin dilación indebida los datos 
personales cuando concurra alguna de las circunstancias siguientes: a) los datos personales ya no sean necesarios en relación con los fines para los que fueron recogidos o tratados de otro modo; b) el interesado retire el consentimiento en que se basa el tratamiento de conformidad con el artículo 6o., apartado 1, letra a), o el artículo 9o., apartado 2, letra a), y este no se base en otro fundamento jurídico; c) el interesado se oponga al tratamiento con arreglo al artículo 21, apartado 1, y no prevalezcan otros motivos legítimos para el tratamiento, o el interesado se oponga al tratamiento con arreglo al artículo 21, apartado 2; d) los datos personales hayan sido tratados ilícitamente; e) los datos personales deban suprimirse para el cumplimiento de una obligación legal establecida en el Derecho de la Unión o de los Estados miembros que se aplique al responsable del tratamiento; f) los datos personales se hayan obtenido en relación con la oferta de servicios de la sociedad de la información mencionados en el artículo 8o., apartado 1.

2. Cuando haya hecho públicos los datos personales y esté obligado, en virtud de lo dispuesto en el apartado 1, a suprimir dichos datos, el responsable del tratamiento, teniendo en cuenta la tecnología disponible y el coste de su aplicación, adoptará medidas razonables, incluidas medidas técnicas, con miras a informar a los responsables que estén tratando los datos personales de la solicitud del interesado de supresión de cualquier enlace a esos datos personales, o cualquier copia o réplica de los mismos.

A partir de este momento, la Directiva 95/46 quedó sin vigencia, entre otras cosas, por no estar a la altura de los nuevos retos relacionados con las tecnologías y con la protección de derechos humanos, así como por su alcance jurídico: mientras que los reglamentos de la Unión Europea tienen alcance general en su sentido material de obligatoriedad y homogeneidad para todos los miembros de la Unión Europea, la Directiva 95/46 consideraba ciertos parámetros que necesitaban transposición por parte de los Estados miembros. Por ello, la adopción de este Reglamento especial consideró, además, el compromiso de los Estados con los aspectos tecnológicos que la Directiva 95/46 no contempló en su momento, dejando de lado tener que recurrir a la jurisprudencia nacional o europea en la materia.

Otra diferencia también se puede apreciar en el ámbito territorial, ya que el Reglamento General va más allá tratando de dilucidar ciertos puntos, como lo es la posibilidad de aplicarse territorialmente a los responsables del tratamiento de datos, aun cuando se localicen fuera de la Unión Europea, lo cual, a diferencia de la Directiva 95/46, era difícil de sostener.

Esta obra está bajo una Licencia Creative Commons

Atribución-NoComercial-SinDerivar 4.0 Internacional, IIJ-UNAM.

Boletín Mexicano de Derecho Comparado, núm. 156, pp. 1449-1475. 
Siguiendo esta distinción, lo que sigue es preguntarse si el derecho al olvido, considerado así en el Reglamento General, incluye una facultad adicional a las de cancelación y oposición, o bien, por el contrario, se trata de una facultad nueva, adicional a las anteriores, la de supresión, pues de esto dependerán en gran medida las futuras resoluciones judiciales que se den.

Para el análisis respectivo, se puede empezar a partir de lo que el Reglamento no considera que es lo que algunos autores denominaron una "fecha de expiración" (véase Orza y Ruiz 2011), a través de la cual la cancelación de los datos personales o la prohibición de utilizarlos no requería de la actuación del titular de los datos, sino que bastaba la condición de que éstos se hubieran almacenado durante un cierto periodo de tiempo, "fecha de expiración". En otras palabras, haciendo "borrón y cuenta nueva" (véase Arenas 2013). Queda claro, entonces, que el Reglamento General necesita un accionar por parte del titular, a fin de que éste solicite expresamente su deseo de eliminar sus datos; es decir, el Reglamento General sí "reconoce un derecho de los interesados a que sus datos sean suprimidos por el responsable del tratamiento en determinadas circunstancias y salvo que se den otros supuestos contemplados en el ámbito de las excepciones de este derecho" (Álvarez Caro 2015, 241). Además, la normativa también "recoge una obligación para los responsables del tratamiento de informar a otros responsables que estén tratando los datos, con el fin de que tomen medidas y supriman toda réplica, copia o enlace a los mismos" (Álvarez Caro 2015, 241).

En resumen, el artículo 17 reconoce expresamente el derecho de supresión, que tiene por objeto garantizar el derecho de los sujetos titulares de los datos a obtener, sin dilación indebida, la supresión de los datos personales que le conciernan del responsable del tratamiento en determinados supuestos (Gómez 2016, Reglamento UE 2016/679). La novedad en este sentido que aporta el Reglamento General es que si los datos se han hecho públicos, el responsable de dicha publicación, además de suprimirlos de sus propios sistemas, adoptará todas las medidas razonables, incluidas las de carácter técnico, para informar a los terceros que estén tratando dichos datos, de que deben suprimir cualquier enlace a estos datos personales, o cualquier copia o réplica de éstos (Guerrero 2006).

El derecho de supresión, sin embargo, debe entenderse diferente a las facultades de cancelación y oposición, pero junto a ellas. Es decir, 
como una facultad aledaña. En cuanto a la facultad de cancelación, se debe suspender el tratamiento cuando haya transcurrido un periodo de tiempo que lo haga inadecuado. La facultad de oposición, por su parte, señala que el interesado tendrá derecho a oponerse por motivos relacionados con su situación particular. La consecuencia, por tanto, es que el responsable deje de tratar los datos personales, salvo motivos imperiosos; pero de esta facultad no puede derivarse un derecho a olvidar. El término "olvidar" se puede lograr sólo cuando los contenidos virtuales se borran definitivamente, lo que sucede con la facultad de supresión. Olvidar es el objetivo que se pretende conseguir al ejercer la facultad de supresión de los datos. En consecuencia, una vez borrados, pueden ser olvidados, porque se ignoran, se desconocen; es una especie de desprenderse de ellos. Por tanto, para olvidar, se deben llevar a cabo acciones tendentes a conseguir ese objetivo, que puede ser la supresión, eliminación, cancelación o bloqueo, que se pueden conseguir con el derecho al olvido.

En conclusión, olvidar no es borrar; pero para olvidar hay que borrar. En cuanto al derecho al olvido, el Reglamento General lo prevé como una nueva facultad general de borrado. Es decir, el derecho al olvido no sólo se limita a las facultades de cancelación y oposición aplicadas en Internet, sino que se extiende a la supresión de los datos. El derecho al olvido es, entonces, la consecuencia de ejercer dicha facultad de borrado o de supresión. Es un derecho, en efecto, toda vez que al ser suprimidos los datos se pueden olvidar. El derecho al olvido es la última respuesta a la necesidad surgida en Internet de preservar ciertos derechos fundamentales, como la protección de datos personales o la privacidad de las personas. No hay otra manifestación más clara de afrontar el presente que olvidar virtualmente el pasado.

Sobre esta idea, el Reglamento General excluye la posibilidad de considerarlo un derecho autónomo, y, por el contrario, se sostiene como un derecho transversal ${ }^{6}$ o instrumental, en el sentido de que al lado de las

6 Esta posición del derecho al olvido como derecho subjetivo transversal supone que puede invocarse toda vez que por el uso de un dato personal se cause un perjuicio a su titular, permitiéndole cierta libertad de actuación en uno u otro derecho. En consecuencia, su naturaleza no sólo estaría vinculada al derecho a la protección de datos, ya que sostenerlo así equivaldría a sujetarlo necesariamente a un tratamiento de datos, lo que implicaría que otros derechos de la personalidad no se beneficiarán de su garantía. Piénsese, por ejemplo, cuando se publica una noticia en Internet en ejercicio del derecho a la información, pero 
facultades de cancelación y oposición en Internet el derecho al olvido se erige como una facultad adicional que implica la eliminación completa de los datos.

Visto así, el derecho al olvido como una facultad general de borrado no está exento de críticas. El principal argumento en contra de dicha postura es que "supondría hacer posible borrar o reescribir la historia. Implicaría otorgar a las personas la facultad de alterar la objetividad de lo ocurrido, modificando su contenido o imposibilitando a los demás el acceso a sus datos" (Mieres 2014, 25). También se ha afirmado que el derecho al olvido como facultad de borrado constituiría un obstáculo al funcionamiento de los canales de información que necesitan los ciudadanos para desarrollar con responsabilidad y autonomía sus actividades, toda vez que las relaciones sociales se basan en la información que tenemos unos de otros, y la única opción con que cuenta cada persona depende, en parte, del grado de confianza que inspire el historial de sus logros (Mieres 2014). Así, el derecho al olvido constituiría una "privacidad por defecto", invirtiendo la carga de la prueba del individuo al responsable del tratamiento de los datos (CESE, párr. 89). La privacidad por defecto implicaría un borrado por defecto; esto es, de manera automática se liberaría toda la información personal mediante la introducción de fechas de caducidad por parte de los usuarios (Mieres 2014). Una opción como ésta presenta problemas, porque para los usuarios puede ser difícil operar técnicamente una fecha de caducidad, más aún cuando ni siquiera son conscientes de que existe información sobre ellos.

Cabe mencionar que el Reglamento General no ha tenido aplicabilidad directa a partir de su entrada en vigor, pero se puede hacer mención del caso 545/2015, del 15 de octubre de 2015 (caso El País), resuelto por el Tribunal Supremo español (TS), a través del cual se puede identificar un pronunciamiento expreso del denominado derecho al olvido. Los hechos del presente caso se suscitaron a partir de la demanda ante el juzgado de primera instancia de dos personas a Ediciones El País, S. L., por el tratamiento de sus datos personales (concretamente, el nombre y apellido) a través de una noticia en la que se señalaba que en el pasado habían sido

tal publicación, refiriéndose a una persona en concreto, debido a la utilización de frases injuriosas y denigrantes para descalificarla, vulneren su derecho al honor. En este ejemplo, el derecho al olvido en su carácter transversal sí podría ser invocado bajo el derecho al honor, en el ejemplo anterior. 
condenados por el delito de contrabando, y cuya información era de acceso público en la hemeroteca digital del diario El País y en otros motores de búsqueda, como Google y Yahoo, como consecuencia de su inclusión en dichas bases de datos. Resumidamente, los demandantes señalaron que la difusión de la noticia publicada por el diario El País suponía una vulneración de sus derechos al honor, a la intimidad y a la protección de datos personales, por lo que solicitaron, entre otras cosas, que se condenara a Ediciones El País a implantar las medidas tecnológicas necesarias para impedir que la página web que contenía información sobre las personas fuera indexada por los buscadores de Internet y por el propio buscador interno del diario El País. Cabe mencionar que dentro de la demanda inicial, los demandantes no señalaron la posible vulneración de su derecho al olvido.

El juez de primera instancia dictó sentencia y declaró acreditada la vulneración de los derechos al honor, a la intimidad y a la protección de datos personales de los demandantes, y condenó a Ediciones El País al cese inmediato de la difusión de dicha noticia y a implantar medidas tecnológicas adecuadas para impedir su difusión en otros buscadores, como Google o Yahoo, pues consideró que las personas habían sido condenadas por un delito que no tenía relevancia en el presente, y que, por el contrario, su difusión lesionaba sus derechos. El juzgado hizo hincapié en la prevalencia de los derechos de las personas sobre el interés económico del diario El País, pues el derecho a la información alegado por esta última se obtuvo cuando se publicó la noticia en su versión impresa años atrás. Además, las personas no tenían relevancia pública, por lo que no podía negarse su derecho al olvido.

El diario El País impugnó la sentencia, pero la audiencia provincial la desestimó y declaró estimar la impugnación de los demandantes en el sentido de condenar al diario El País a cesar en el uso de sus datos personales en el código fuente de la página web que contenía la noticia. De esta manera, Ediciones El País interpuso un recurso de casación formulando que la noticia puesta en la hemeroteca digital tiene interés público, puesto que se trata de información relativa a la comisión de delitos, y, por lo cual, el transcurso del tiempo no convierte la noticia en irrelevante o carente de interés público, y, en cuanto a la protección de datos, su actuación constituye un tratamiento de datos con fines periodísticos, amparada por la libertad de información.

Esta obra está bajo una Licencia Creative Commons

Atribución-NoComercial-SinDerivar 4.0 Internacional, IIJ-UNAM.

Boletín Mexicano de Derecho Comparado, núm. 156, pp. 1449-1475. 
La Sala del TS resolvió la litis del presente caso, y delimitó el enjuiciamiento por el tratamiento de datos personales derivado de la digitalización de la hemeroteca del diario en que dicha información fue publicada. En ese sentido, el diario El País es responsable del tratamiento de datos de las personas demandantes contenidos en la página web, y tiene la obligación de respetar las exigencias derivadas del principio de calidad de los datos, contenidas en la normativa europea. ${ }^{7}$ Por lo anterior, se debe ponderar entre el ejercicio de la libertad de información que supone la edición y puesta a disposición del público de las hemerotecas digitales que otorga un ámbito de protección menos intenso que las noticias de actualidad y el respeto a los derechos de la personalidad. De ahí que el Tribunal Supremo, siguiendo los criterios de la STJUE del caso Google, señaló que los derechos al respeto a la vida privada y familiar, así como los datos personales, deben prevalecer sobre el interés del público, más aún cuando los hechos objeto de la información tuvieron lugar más de veinte años antes, por lo que actualmente carecen de interés histórico o relevancia pública.

En cuanto al derecho al olvido, el Tribunal Supremo tomó una postura en el sentido de definir, primero, lo que tal derecho no puede ser, y, en segundo lugar, lo que ese derecho sí es. Es decir, se aproxima a su configuración jurídica delimitando sus contornos. Así, señaló que lo que no puede amparar es que

...cada uno construya un pasado a su medida, obligando a los editores de páginas web o a los gestores de los motores de búsqueda a eliminar el tratamiento de sus datos personales cuando se asocian a hechos que no se consideran positivos. Tampoco justifica que aquellos que se exponen a sí mismos públicamente puedan exigir que se construya un currículo a su gusto, controlando el discurso sobre sí mismos, eliminando de Internet las informaciones negativas, "posicionando" a su antojo los resultados de las búsquedas en

7 La normativa europea que menciona la Sala es la Constitución española, el Convenio Europeo de Derechos Humanos, la Carta de Derechos Fundamentales de la Unión Europea, el Convenio 108 del Consejo de Europa del 28 de enero de 1981, la Directiva 1995/46/CE, del 24 octubre, del Parlamento Europeo y del Consejo de la Unión Europea, de protección de las personas físicas en lo que respecta al tratamiento de datos personales y a la libre circulación de estos datos, y la Ley Orgánica 15/1999, del 13 de diciembre, de Protección de Datos de Carácter Personal, en la interpretación que de dichas normas han hecho tanto el Tribunal Constitucional y el Tribunal Supremo como el TJUE y el Tribunal Europeo de Derechos Humanos. Se puede notar que se hace referencia a la Directiva y no al Reglamento General de Protección de Datos Personales. 
Internet, de modo que los más favorables ocupen las primeras posiciones. De admitirse esta tesis, se perturbarían gravemente los mecanismos de información necesarios para que los ciudadanos adopten sus decisiones en la vida democrática de un país (fundamento de derecho sexto, párrafo octavo de la sentencia).

Lo que sí puede amparar, en cambio, es que el afectado

...cuando no tenga la consideración de personaje público, pueda oponerse al tratamiento de sus datos personales que permita que una simple consulta en un buscador generalista de Internet, utilizando como palabras clave sus datos personales tales como el nombre y apellidos, haga permanentemente presentes y de conocimiento general informaciones gravemente dañosas para su honor o su intimidad sobre hechos ocurridos mucho tiempo atrás, de modo que se distorsione gravemente la percepción que los demás ciudadanos tengan de su persona, provocando un efecto estigmatizador e impidiendo su plena inserción en la sociedad, inserción que se vería obstaculizada por el rechazo que determinadas informaciones pueden causar en sus conciudadanos (fundamento de derecho sexto, párrafo octavo de la sentencia).

La sentencia recordó las dos medidas impuestas por la audiencia provincial: la eliminación de sus datos personales del código fuente de la página web que contiene la noticia, suprimir sus nombres y apellidos, no permitir siquiera que consten sus iniciales, y la adopción de medidas técnicas que eviten que la información pueda ser indexada por el propio buscador interno cuando se busque información utilizando el nombre y los apellidos de las personas demandantes. Sin embargo, señaló que la primera de ellas supone un sacrificio desproporcionado del derecho a la libertad de información, puesto que el derecho al olvido digital no puede suponer una censura retrospectiva de las informaciones correctamente públicas en su día. Y agregó que

[L]as hemerotecas digitales gozan de la protección de la libertad de información, al satisfacer un interés público en el acceso a la información. Por ello, las noticias pasadas no pueden ser objeto de cancelación o alteración. El TEDH ha considerado que la protección de las hemerotecas digitales por el artículo 10 del Convenio implica que las noticias pasadas contenidas en ellas, a pesar de que su contenido pueda afectar a los derechos de las personas, no pueden ser eliminadas... Por tanto, la integridad de los archivos digitales es 
un bien jurídico protegido por la libertad de expresión que excluye las medidas que alteren su contenido eliminando o borrando datos contenidos en ellos, como puede ser la eliminación de los nombres de las personas que aparecen en tales informaciones o su sustitución por las iniciales" (fundamento de derecho séptimo, párrafo tercero de la sentencia).

En cuanto a la segunda medida, señaló que también supone un sacrificio desproporcionado, pues dichos motores de búsqueda sirven para consulta interna de la información, y no pueden asimilarse a los motores de búsqueda de Internet, como Google o Yahoo, por lo que desestimó tal medida.

Como se puede observar, el TS hace referencia al derecho al olvido en su sentencia y coincide con la opinión de que tiene como finalidad "impedir la configuración de una historia lineal e ininterrumpida de la persona en la red o, al menos, facultar al individuo para controlar el grado de trazabilidad de su vida" (Mieres 2014, 8). Sin embargo, tal facultad es exclusiva de los particulares, o al menos así lo señala el TS cuando se refiere a que el afectado "no tenga la calidad de personaje público"; por eso, el derecho al olvido es un poder de las personas, pero sólo de aquellas que no son personajes públicos, para avanzar en el tiempo sin tener que ser discriminados por hechos que tuvieron importancia en una época y espacio determinados, no debiendo ser un impedimento para continuar con el libre desarrollo de su persona; por ejemplo, en su vida cotidiana, para conseguir un trabajo, etcétera.

La construcción normativa que se hace del derecho, sin embargo, se realiza a partir de la jurisprudencia hasta el momento existente, y no menciona al Reglamento General, aun cuando para esa época había sido aprobado. Lo que es sobresaliente de esta sentencia es, sin duda, el peligro que sobresale a la luz del derecho al olvido si no se limita, y puede, por ejemplo, "abrir la puerta de forma peligrosa para eliminar la memoria histórica de un país", ${ }^{8}$ que más allá de procurar un respeto a la vida privada, atienda a caprichos políticos en contra del interés general. El TS reconoció el derecho al olvido como una facultad general de borrado, pero con sus respectivos límites.

8 Así se ha expresado la preocupación de varios medios de comunicación y activistas ante la posibilidad de ejercer el derecho al olvido, para quienes se debe garantizar la transparencia y la apertura de la información más que su olvido. Véase Álvarez Acevedo (2015). 


\section{RECONOCIMIENTO FINAL DE UN DERECHO AL OLVIDO COMO FACULTAD GENERAL DE BORRADO Y SUS NOTAS DISTINTIVAS}

La necesidad de que exista un derecho al olvido para suprimir los datos contenidos en Internet también exige que se dé bajo determinados criterios, pues "ante una cuestión global, se requieren principios globales" (Arenas 2013, 331). Estos principios, que también se denominan "criterios de claridad" (Mieres 2014, 47), son los que van a definir su propia esencia, pero de la misma manera "a la hora de determinar el resultado de la ponderación evitarían las consecuencias negativas de un exceso de celo en la protección del derecho al olvido" (Mieres 2014, 47).

\section{Que los datos personales se encuentren disponibles en Internet}

La primera nota distintiva es que los datos personales que se quieran eliminar se encuentren disponibles en Internet. Se trata de aquellos relacionados con fotos, actualizaciones de estados, entradas de bitácoras, participaciones en foros, revelaciones personales, acciones vergonzosas publicadas en las redes sociales (Pere 2012) o noticias pasadas, todo lo cual, a su vez, es publicado, enviado o retransmitido desde cualquier parte del mundo sin siquiera, a veces, ser conscientes de ello.

Añadida a esta problemática, hay que considerar la importancia creciente de la computación en la nube, pues la mayoría de los datos se almacenan en sofisticados ficheros electrónicos a los que sólo pocos tienen acceso. Junto a ello, no debe perderse de vista la eterna y perfecta memoria virtual en medio de ese universo infinito de informaciones frente a la limitada capacidad humana para contrarrestar la conservación y difusión constante de los hechos del pasado (Pere 2015). Además, en Internet existe un elevado riesgo de descontextualización de los datos personales compartidos, que se produce cuando el emisor divulga o publica en la red, datos que pueden ser fácilmente malinterpretados (Pere 2015).

El aspecto afectivo, pasional o emocional en la transmisión de datos personales también juega un papel determinante (Pere 2012). Muchas veces se les da un tratamiento especial a los datos dependiendo de quién provengan; esto es, los datos son discriminados con base en nuestras con-

Esta obra está bajo una Licencia Creative Commons

Atribución-NoComercial-SinDerivar 4.0 Internacional, IIJ-UNAM.

Boletín Mexicano de Derecho Comparado, núm. 156, pp. 1449-1475. 
vicciones o creencias; por ejemplo, políticas ideológicas, sentimentales, culturales, entre otras, lo que lleva a darles mayor o menor credibilidad a los datos que se reciben si provienen de un contacto, de un familiar o de un medio de comunicación. En el caso El País se discutió sobre la veracidad que deben tener los datos, como parte de los requisitos de calidad de su tratamiento, pues como señaló el TS, "el hecho de que el derecho al olvido esté ligado al arrepentimiento o al derecho al borrado, se puede llegar a la conclusión de que parte de la premisa de veracidad de los datos" (Álvarez Caro 2015, 68). La realidad a la que se ha tenido que hacer frente con el derecho al olvido responde al riesgo de vernos sometidos a escrutinios y críticas constantes por informaciones que no nos favorecen. Sin embargo, dado que el objetivo es olvidar, podría admitirse que se olvidan hechos pasados, antecedentes de nuestra historia de vida, acontecimientos de una realidad pasada, que, de no resultar verdaderos, no se justificaría su borrado.

Cuando, por el contrario, se publiquen hechos falsos, por ejemplo, que puedan ocasionar un daño moral a la reputación de su titular, lo que procedería es corregir los datos mediante una solicitud de rectificación, pero no mediante el derecho al olvido, pues el conflicto principal son posibles violaciones a otros derechos, como el honor, la intimidad o la propia imagen a que se ven sometidas las personas por la publicación de informaciones falsas, injuriosas o carentes de veracidad.

\section{Que los datos personales sean objeto de tratamiento}

El segundo criterio de claridad a considerar para poder ejercer el derecho de supresión o derecho al olvido en Internet es el propósito que se pretende con los datos disponibles en Internet, y que no es otro que un tratamiento. En la STJUE, en el caso Google, el tratamiento de datos es el elemento central para entender las razones que tuvo el TJUE para responsabilizar a Google, y, en cambio, no hacer lo mismo con el editor del sitio de Internet por la publicación de la noticia. En primer lugar, para el TJUE, un tratamiento de datos es

...cualquier operación o conjunto de operaciones, efectuadas o no mediante procedimientos automatizados, y aplicadas a datos personales, como la 
recogida, registro, organización, conservación, elaboración o modificación, extracción, consulta, utilización, comunicación por transmisión, difusión o cualquier otra forma que facilite el acceso a los mismos, cotejo o interconexión, así como su bloqueo, supresión o destrucción" (de acuerdo con lo señalado por el entonces artículo 2 b) de la Directiva 95/46 y el artículo 4o., apartado 2 del Reglamento General).

Tal lista no es taxativa, pues basta con ejecutar cualquiera de las acciones enumeradas para ser responsable del tratamiento; así lo entendió el TJUE desde la sentencia Lindqvist (2003, párr. 25), en la que declaró que "la conducta consistente en hacer referencia, en una página web, a datos personales debe considerarse un tratamiento; en el sentido del artículo 2 b) de la derogada Directiva 95/46".

En el caso Google, el TJUE señaló que

...al explorar Internet de manera automatizada, constante y sistemática en busca de la información que allí se publica, el gestor de un motor de búsqueda (en este caso Google), "recoge", tales datos que "extrae", "registra" y "organiza" posteriormente en el marco de sus programas en forma de listas de resultados de sus búsquedas (Google versus AEPD, párr. 28).

Ya que estas acciones corresponden a las enunciadas en el artículo 2 b) de la entonces Directiva 95/46, existe un tratamiento en tal sentido.

No contradice la apreciación anterior el hecho de que estos datos hayan sido ya objeto de publicación en Internet y el motor de búsqueda no los modifique (Google versus AEPD, párr. 29), pues una excepción general a la aplicación de la entonces Directiva 95/46 en tal supuesto dejaría esta última en gran medida vacía de contenido (Google versus AEPD, párr. 30). Por el contrario, el tratamiento por parte del editor de la página web, que consiste en la publicación de información relativa a una persona física, "puede efectuarse con fines exclusivamente periodísticos y beneficiarse, de este modo, en virtud del artículo 9o. de la Directiva 95/46, de las excepciones a los requisitos que ésta establece" (Google versus AEPD, párr. 28). Siguiendo este criterio, el TJUE no responsabilizó al editor de la página web en la que se ubicaba también la información personal que se pretendía eliminar. 


\section{Que el responsable tenga un "papel decisivo en la difusión global" de los datos personales}

Es importante conocer quiénes son los sujetos obligados del tratamiento de los datos en Internet, pues de ello dependerá la atribución de responsabilidades, y, consecuentemente, a ellos se podrá dirigir la solicitud de supresión de los datos. El numeral 2, d), de la antigua Directiva 95/46 empleaba el término responsable para referirse a "la persona física o jurídica, autoridad pública, servicio o cualquier otro organismo que sólo o conjuntamente con otros determine los fines y los medios del tratamiento de datos personales". Que "determine los fines y los medios" fue motivo de desacuerdo en el caso Google, entre el abogado general y el TJUE. Para el abogado general, ninguna duda plantea que los buscadores de Internet, en este caso Google Search, lleve a cabo un tratamiento de datos. Sin embargo, en la medida en que se trata simplemente de una herramienta de localización de información, no ejerce ningún control sobre los datos incluidos en las páginas web de terceros, pues no es "consciente" de la existencia de datos personales. Más aún, no tiene relación con el contenido de páginas web disponibles en Internet en las que pueden aparecer datos personales y carece de medios para modificar la información en los servidores de alojamiento. Motivos todos por los que no puede ser considerado responsable del tratamiento (Google versus AEPD, párr. 84-86).

Para el TJUE, en cambio, "los motores de búsqueda desempeñan un papel decisivo en la difusión global de datos en la medida en que facilitan su acceso a todo internauta que lleva a cabo una búsqueda a partir del nombre del interesado" (Google versus AEPD, párr. 36 y 87). Además, toda vez que por la actividad del motor de búsqueda se puede afectar significativamente y de manera adicional a los derechos fundamentales de respeto a la vida privada y protección de datos personales, el gestor de este motor determina los fines y los medios de esta actividad (Google versus AEPD, párr. 36-38), requisito indispensable en términos de la entonces Directiva 95/46 para ser considerado responsable.

De lo establecido por el TJUE hay dos elementos que determinan la especial incidencia del motor de búsqueda: a) su papel decisivo en la difusión, y b) la afectación significativa y de manera adicional a los derechos fundamentales. En cuanto al primer elemento, "Google entendió muy bien desde el principio que la organización de toda esa información tenía 
un gran valor" (Hernández 2014, 3), que se traduce en un poder o control sobre otra persona; por tanto, la actividad de Google consiste en ofrecer una lista de resultados ordenada con base en un algoritmo que calcula la relevancia de las páginas web según las preferencias de los usuarios. Los datos indexados se almacenan, y una vez que se utiliza la herramienta del buscador, en este caso Google Search, se genera una lista de los contenidos almacenados, al mismo tiempo que se aprovecha la lista para la promoción y difusión de espacios publicitarios, de lo cual Google deriva su rentabilidad y ganancias.

Estas consideraciones toman mayor sentido en la actual sociedad de la información y del conocimiento, en que "los motores de búsqueda constituyen la puerta de acceso a Internet" (Mieres 2014, 41) al mismo tiempo que contribuyen a dar publicidad a productos y servicios a los clientes a través de sus gustos y necesidades. El orden de la lista de aparición de los resultados de un buscador es esencial para el papel activo y no sólo neutral que desempeñan en la búsqueda de la información personal. ${ }^{9}$ Además, tanto la búsqueda como la presentación de la información ya son de por sí un tratamiento adicional al que se ha hecho en origen en cada página web de terceros (véase el comentario de Boix 2015). Sin estas herramientas, la tarea de buscar información que nos interesa en el universo de páginas web existentes simplemente estaría fuera del alcance de las capacidades del ciudadano medio (Mieres 2014).

Estas consideraciones son retomadas en el caso El País, en el que el TS hace una distinción entre los buscadores internos y aquellos en Internet, señalando que "estos motores de búsqueda internos de las hemerotecas digitales solo sirven para localizar la información contenida en el propio sitio web una vez que el usuario ha accedido a dicho sitio web. No son por tanto asimilables a los motores de búsqueda de Internet tales como Google, Yahoo, Bing, etc.” (Sentencia 545/2015, fundamento de derecho 7.4), y agrega:

...el riesgo para los derechos de la personalidad de las personas afectadas por la información guardada en la hemeroteca digital no radica tanto en que la

9 Entre los defensores de la posición neutral de Google se encuentra el abogado general, el mismo Google y autores, como Guichot, para quien "resulta altamente cuestionable atribuir a los buscadores la responsabilidad de garantizar la cancelación de datos y no a los responsables de la publicación de la información”. Cfr. Guichot (2013).

Esta obra está bajo una Licencia Creative Commons

Atribución-NoComercial-SinDerivar 4.0 Internacional, IIJ-UNAM.

Boletín Mexicano de Derecho Comparado, núm. 156, pp. 1449-1475. 
información sea accesible a través del motor de búsqueda interno del sitio web en que se encuentra alojada, pues se trata de una búsqueda comparable a la que efectuaban quienes acudían a las viejas hemerotecas en papel, como en la multiplicación de la publicidad que generan los motores de búsqueda en Internet, y en la posibilidad de que mediante una simple consulta utilizando los datos personales, cualquier internauta pueda obtener un perfil completo de la persona afectada.

De esta manera, el TS concluyó que a partir de los motores de búsqueda internos no se puede obtener un perfil tan detallado y preciso como el que se puede generar a partir de los motores en Internet, y, en consecuencia, no son asimilables en cuanto al tratamiento de datos, porque tampoco generan los mismos efectos o daños para los derechos de las personas.

En cuanto al segundo elemento; esto es, la afectación significativa y adicional a los derechos fundamentales, el TJUE en la sentencia en contra de Google advirtió que el carácter ubicuo de los motores de búsqueda en la sociedad moderna afecta potencialmente a una multitud de aspectos de la vida privada, que sin dicho motor no se habrían interconectado o sólo podrían haberlo sido muy difícilmente, permitiendo, de este modo, establecer un perfil más o menos detallado de la persona (Google versus AEPD, párr. 80). Los motores de búsqueda han ofrecido ser una herramienta con una importancia evidente, que facilita el acceso a casi cualquier información disponible en la red, sea o no personal. De manera que la "gravedad potencial de esa injerencia" (Google versus AEPD, párr. 81) en los derechos fundamentales hace que "estos derechos adquieran un especial peso y relevancia a la hora de ponderarlos con otros intereses con los que entran en conflicto" (Mieres 2014, 444).

En el Reglamento General se estable la obligación del responsable del tratamiento que haya difundido los datos personales, de informar a los controladores que procesan los datos sobre la solicitud del interesado de suprimir todos los enlaces a los datos personales, enlaces, copias o reproducción de ellos (artículo 17, apartado 2); esto es, convertir al responsable del tratamiento en responsable de los datos (Arenas 2013). Puede entenderse esta obligación para el caso de las transferencias o comunicaciones de datos en que el responsable ha trasmitido los datos conscientemente a otra persona distinta del titular; no podría decirse lo 
mismo para el caso de los buscadores, para los que supondrán esfuerzos desproporcionados para su eficaz cumplimiento, pues aun aceptando que son responsables, parece desproporcionada la obligación adicional de comunicar a terceros la solicitud de derecho al olvido del titular. Es cierto que los buscadores en el cumplimiento de su responsabilidad deben llevar a cabo las medidas necesarias para contestar una solicitud de derecho al olvido, pedir que a su vez puedan controlar la multiplicación de los datos a terceros que realizan igualmente un tratamiento de ellos excedería el marco de sus responsabilidades. ${ }^{10}$ Sobre esto, el Reglamento General se ha pronunciado por construir el derecho al olvido en Internet sobre las obligaciones del responsable principal que ha hecho públicos los datos, de manera que el derecho al olvido no se garantiza con un procedimiento en el que el interesado se dirige y le exige al buscador que cancele los datos, sino que tiene que ejercer su derecho ante el responsable que los publicó inicialmente (Troncoso 2012). ${ }^{11}$

\section{Que los datos personales se vuelvan incompatibles por el paso del tiempo}

La cuarta nota distintiva está relacionada con el factor tiempo, que es uno de los elementos más importantes a considerar para el ejercicio del derecho al olvido. El tiempo constituye una barrera de reserva que permite al individuo, confiar en que los datos personales que una vez fueron públicos o conocidos, pero han dejado de ser relevantes y no son objeto de atención pública, se consideren como reservados, y no como res nullius publicable por cualquiera en cualquier momento, salvo que concurra un interés público en esa difusión (Mieres 2014).

10 "El gestor de este motor, como persona que determina los fines y los medios de esta actividad, debe garantizar, en el marco de sus responsabilidades, de sus competencias y de sus posibilidades, que dicha actividad satisface las exigencias de la Directiva 95/46" (Google versus AEPD, párr. 38).

11 "De esta forma existe también una responsabilidad secundaria del buscador... pero la responsabilidad principal la tiene la fuente original... que ha publicado reiteradamente en un diario oficial o en Internet datos excesivos... para la finalidad y que los mantiene publicados pese a que se hay cumplido ésta, negándose a adoptar ningún mecanismo técnico que impida la indexación, en cambio, los buscadores son básicamente herramientas técnicas, y que tienen sin duda una responsabilidad, pero que no es, en absoluto, la principal". $\mathrm{Al}$ respecto véase el estudio que realiza Troncoso (2012).

Esta obra está bajo una Licencia Creative Commons

Atribución-NoComercial-SinDerivar 4.0 Internacional, IIJ-UNAM.

Boletín Mexicano de Derecho Comparado, núm. 156, pp. 1449-1475. 
Se habla de una "expectativa razonable de reserva" (Mieres 2014, 15) para referirse a la razonabilidad de que los datos en Internet no sean accesibles indefinidamente, pues resultaría irrazonable y desproporcionado que las personas se encontraran expuestas a un escrutinio público toda su vida. En este sentido, "los medios de comunicación tienen un deber de actualización o contextualización de aquellas noticias publicadas y accesibles en sus hemerotecas digitales que devengan inexactas o incompletas con el paso del tiempo, limitando el derecho al olvido de los afectados" (Mieres 2014, 39). Es verdad que "el recuerdo constante y la difusión de hechos pasados, cuando estos no han sido nunca de interés público o con el paso del tiempo lo han perdido, puede afectar al derecho a la protección de datos" (Pere 2012, 121). Este supuesto está referido a los datos, en particular, cuando son inadecuados, no pertinentes o excesivos en relación con los fines y el tiempo transcurrido (Google versus AEPD, párr. 93), de manera que se crea un "derecho pasivo a ser olvidado" para los responsables de los datos (véase la obra Álvarez Caro 2015).

A juicio del TJUE, el paso del tiempo afecta a la calidad de los datos, ya que inicialmente se trataba de informaciones pertinentes, adecuadas y no excesivas, que pueden dejar de serlo, y la necesidad por haberse cumplido y agotado la finalidad para la que se recabaron. Además, la motivación de las circunstancias concretas personales que debe acompañar el ejercicio del derecho no exige acreditar perjuicio alguno, sino un acto de voluntad vinculado a las condiciones personales (véase Rallo 2014). En el mismo sentido se pronunció el TS en el caso El País; señala que

...el factor tiempo tiene una importancia fundamental en esta cuestión, puesto que el tratamiento de los datos personales debe cumplir con los principios de calidad de datos no solo en el momento en que son recogidos e inicialmente tratados, sino durante todo el tiempo que se produce ese tratamiento. Un tratamiento que inicialmente pudo ser adecuado a la finalidad que lo justificaba puede devenir con el transcurso del tiempo inadecuado para esa finalidad, y el daño que cause en derechos de la personalidad como el honor y la intimidad, desproporcionado en relación al derecho que ampara el tratamiento de datos (TS, Sentencia 545/2015, fundamento de derecho 6.3).

Asimismo, y frente al argumento de que los datos deben ser eliminados pasada la finalidad de su tratamiento, cabría reflexionar si se deben someter los datos a una "fecha de caducidad" (Álvarez Caro 2015). Con 
respecto a este punto, el término "tiempo" es en sí mismo indeterminado, por lo cual su control no resulta sencillo, y para llevarlo a cabo es necesario atender, no sólo a la finalidad del tratamiento, sino también a los efectos que puede generar en su titular si los datos no son borrados. En la medida en que tales efectos puedan calcularse, se deberá hacer una ponderación sobre si los datos son realmente notables o trascendentales en la actualidad para seguir con los objetivos que se pretendieron al inicio de su tratamiento o publicación. De acuerdo con el TJUE, en el caso Google la ponderación se debió efectuar en el marco de los artículos 7 f), y 14, primer párrafo, a) de la entonces vigente Directiva 95/46, en el sentido de analizar si debe prevalecer el interés del afectado no sólo sobre el del medio que disponga de los datos, sino también sobre el de los terceros en conocerlos ( Google versus AEPD, párr. 76). En este sentido, el derecho al olvido consistiría en vincular esta evaluación, necesariamente ponderativa, a una evolución diacrónica de la idea de calidad, de manera que el paso del tiempo haría menor la concurrencia de ciertos intereses generales respecto de ciertas publicaciones que afectaban a personas que podrían no tener más remedio que soportarlo por estar justificado por la concurrencia de ese interés público, hasta que llegado el momento primaría el derecho del interesado a no consentir la indexación de ciertos datos (Boix 2015).

\section{Que exista un motivo personal justificado}

La cuestión que se plantea es si debe existir un motivo legítimo del titular de los datos para el borrado o, por el contrario, si debe entenderse que el borrado de los datos se debe producir siempre, a menos que haya razones para no hacerlo. A lo que se debe atender es al principio de finalidad; esto es, que los datos deben borrarse una vez cumplido el propósito de su tratamiento. Lo que se presenta con frecuencia en relación con el derecho al olvido es que el titular desea que sus datos sean borrados antes de que se cumpla con la finalidad, razón por la cual el artículo 21, apartado 1, del Reglamento General, señala que "el interesado tendrá derecho a oponerse en cualquier momento, por motivos relacionados con su situación particular, a que los datos que le conciernan sean objeto de tratamiento, salvo cuando la legislación nacional disponga otra cosa". 


\section{Además,}

...se tendrá que examinar, en particular, si el interesado tiene derecho a que los datos relativos a su persona ya no estén, en la situación actual, vinculados a él por una lista de resultados obtenida tras una búsqueda efectuada a partir de su nombre, la apreciación de la existencia de tal derecho no presupone que la inclusión de los datos en cuestión en la lista de resultados cause un perjuicio al interesado" (Google versus AEPD, párr. 96).

Es decir, el ejercicio del derecho al olvido no exige que se acredite que se haya ocasionado un perjuicio, de modo que la existencia de un daño no es presupuesto necesario de la viabilidad del derecho, sino que basta la consideración subjetiva del interesado de que determinado vínculo a información personal desfasada u obsoleta le puede afectar negativamente (Mieres 2014).

En este sentido, la Agencia Española de Protección de Datos (AEPD) ha puesto de manifiesto la necesidad de que los medios de comunicación usen medidas informáticas para que, en caso de que concurra un interés legítimo de un particular y la relevancia del hecho haya dejado de existir, se evite desde su webmaster la indexación de la noticia por los motores de búsqueda en Internet; de esta manera, se evitaría su divulgación indiscriminada, permanente y, en su caso, lesiva (véase la Resolución AEPD $\mathrm{TD} / 01164 / 2008)$.

En el marco de la STJUE en el caso Google, el TJUE valoró que la información del afectado, al estar disponible por doce años en Internet, sin que tuviera relevancia en el presente, era un motivo suficiente para su eliminación (Google versus AEPD, párr. 93). Precisamente, para el TJUE los derechos de la persona con carácter general prevalecen sobre el interés de los internautas y del propio interés económico del motor de búsqueda (Google versus AEPD, párr. 81);12 no obstante, refiere que el equilibrio puede depender de otros supuestos, tales como la naturaleza de la información, el carácter sensible para la vida privada de la persona afectada y el interés del público en disponer de esa información, que puede variar

12 "Lejos queda la pretensión de los buscadores de avalar su actividad en el ejercicio del derecho fundamental a la información, de atribuirse para sí la consideración de «medio de comunicación» o de pretender su impunidad en su supuesta neutralidad en la red" Rallo (2014, 276). 
en función del papel que desempeñe en la vida pública (Google versus AEPD, párr. 81).

El TJUE reconoció que el borrado de los datos podría tener repercusiones en el interés legítimo de los internautas interesados en conocerlos, pero reconoce, en principio, el interés legítimo de los afectados sobre el de aquéllos, salvo que exista una causa de interés público, que prevalecerá en virtud de la naturaleza de los datos. En efecto, pretender el olvido puede ser diferente cuando se trata de personajes públicos. Incluso, el hecho de que la persona haya dejado la esfera de la cosa pública no determina que deje de ser personaje público, por lo que volver a informar sobre cuestiones pasadas tiene el interés de poder evaluar retrospectivamente la ejecutoria de un cargo público (Mieres 2014). Por tanto, "todo lo relacionado con la profesión por la que la persona es conocida tendrá interés público, tanto si se refiere a sucesos pasados como actuales" (Mieres 2014, 29).

$\mathrm{Al}$ margen de estas ideas, no está exenta la situación de que el motivo del interesado pueda chocar con el del responsable de la publicación en Internet, lo que daría lugar a una colisión de intereses, en la que posiblemente deba intervenir la autoridad. Esa necesaria ponderación con otros valores e intereses permite concretar con exactitud las facultades que el derecho al olvido atribuye a sus titulares (cfr. Pere 2012). Este acotamiento de un motivo razonable puede estar en conexión directa con el derecho del interesado a no tolerar la indexación de sus datos más allá por la falta de pertinencia o exactitud, porque el hecho de que se conserven más tiempo del necesario podría afectar su desenvolvimiento libre y sin discriminación de su proyecto de vida actual.

\section{CONCLusiones}

La preocupación en torno a la eliminación de datos personales no es nueva, ya que algunas legislaciones en este sentido contienen regulaciones sobre la prescripción o cancelación de antecedentes penales que pudieran afectar a las personas. En los últimos años, sin embargo, la preocupación se ha acrecentado debido a la combinación del carácter asincrónico, eterno e inmediato de los datos alojados en Internet, su disposición en cualquier ubicación física y el alto grado de anonimato. 
La necesidad de un derecho al olvido en Internet deriva del carácter abierto, global, ubicuo y poco predecible de Internet, que se traduce en un problema frente al tratamiento masivo de datos personales y la eternidad de la información en la red. Paralelamente, en la actualidad los datos personales se han convertido en el nuevo valor del mercado, lo que supone que se pueda traficar con ellos por su alto contenido económico.

La naturaleza jurídica del derecho al olvido en Internet es la de ser una facultad general de borrado complementaria al derecho de oposición del derecho fundamental a la protección de datos personales. Tal complementariedad del derecho al olvido implica un reforzamiento de los derechos de la personalidad en el espacio virtual. Es el derecho a una "segunda oportunidad" en la vida virtual, que tiene por efecto la eliminación sin demora de datos personales. Se debe considerar, no obstante, la posibilidad del derecho al olvido como derecho transversal de otros derechos, como el honor, la intimidad o la propia imagen, de la que derivaría una tutela concurrente en relación con los datos protegidos en cada ámbito.

A partir de que se habló del derecho al olvido en la STJUE en 2015, ha habido avances significativos, uno de los cuales fue la aprobación del Reglamento General en 2016 y la resolución de casos sobre la materia, de los cuales, se puede decir, a nivel europeo el caso El País se refirió al derecho al olvido como un derecho de supresión o facultad general de borrado. Este caso tuvo relevancia por su pronunciamiento sobre el derecho al olvido siguiendo la normativa europea, pero no el Reglamento General, pues como lo señalan los mismos artículos transitorios, su aplicación se dio dos años después de su aprobación; es decir, en 2018.

\section{REFERENCIAS BIBLIOGRÁFICAS}

Álvarez AcEvedo. 2015. "Google y activistas vs. el INAI: «derecho al olvido» borrará historial negro de políticos". 27 de mayo, disponible en: https://wrere.sinembargo.mx/27-05-2015/1357840.

Álvarez Caro, María. 2015. Derecho al olvido en Internet: el nuevo paradigma de la privacidad en la era digital, Madrid, Reus.

Arenas, Mónica. 2013. "Hacia un futuro derecho al olvido de ámbito europeo", en La protección de los datos personales en Internet ante la innova- 
ción tecnológica, editado por Julián Valero, Navarra, Thomson-ReutersAranzadi.

BoIX, Andrés. 2015. "El equilibrio entre los derecho del artículo 18 de la Constitución, el «derecho al olvido» y las libertades informativas tras la sentencia Google", Revista General de Derecho Administrativo 38.

Cotino, Lorenzo. 2015. "El conflicto entre las libertades de expresión e información en Internet y el derecho a la protección de datos. El derecho al olvido y sus restos: «un falso derecho, a juzgar por un falso tribunal»", en Derecho de la información, editado por Ignacio Bel Mallén, Madrid, CEPC.

Guichot, Emilio. 2013. Derecho de la comunicación, Madrid, Iustel.

Guerrero Picó, María del Carmen. 2006. El impacto de Internet en el derecho fundamental a la protección de datos de carácter personal, Madrid, Civitas.

HERnÁnDEZ, Mario. 2014. "Motores de búsqueda y derechos fundamentales en Internet. La STJUE Google C-131/12, de 13 de mayo de 2014", Revista General de Derecho Europeo 34.

GÓMEz MAYOR, Roberto. 2016. "Contenido y novedades del Reglamento General de Protección de Datos de la UE (Reglamento UE 2016/679)", disponible en: https://libros-revistas-derecho.vlex.es/vid/contenido-novedadesreglamento-general-658068001.

MiERES, Luis Javier. 2014. "El derecho al olvido digital", documento de trabajo. Laboratorio de alternativas disponible en: http://wwrw.falterna tivas.org/laboratorio/documentos/documentos-detrabajo/el-derecho-al-olvido-di gital.

OrZa Linares, Ramón M. y Ruiz TARRÍAS, Susana. 2011. "El derecho al olvido en Internet", en Neutralidad de la red y otros retos para el futuro de Internet, editado por Agustí Cerrillo-I-Martínez, Barcelona, Huygens.

RALLO, Artemi. 2014. El derecho al olvido en Internet, Google versus España, Madrid, CEPC.

ReYes, Mate. 2011. "Las piezas de la memoria", en Diccionario de memoria histórica. Conceptos contra el olvido, editado por Rafael Escudero, Madrid, Catarata.

PERE, Simón. 2012. "El derecho al olvido en el universo 2.0", BID: textos universitaris de biblioteconomia i documentació, núm. 28, disponible en: http:// bid.ub.edu/28/simon2.htm.

PERE, Simón. 2012. El régimen constitucional del derecho al olvido digital, Valencia, Tirant lo Blanch.

Esta obra está bajo una Licencia Creative Commons

Atribución-NoComercial-SinDerivar 4.0 Internacional, IIJ-UNAM.

Boletín Mexicano de Derecho Comparado, núm. 156, pp. 1449-1475. 
PERE, Simón. 2015. El reconocimiento del derecho al olvido digital en España y en la UE. Efectos tras la sentencia del TJUE de mayo de 2014, Barcelona, Bosch. Troncoso, Antonio. 2012. "El derecho al olvido en Internet a la luz de la propuesta de Reglamento General de Protección de Datos Personales de la Unión Europea", Revista de Derecho, Comunicaciones y Nuevas Tecnologías 8. 